\title{
Pneumonia por Chlamydia psittaci: Um Caso Clínico
}

\section{Pneumonia Caused by Chlamydia psittaci: Case Report}

José Luís Castro¹, Filipa Castro Xavier², Joana Valente ${ }^{1}$, Marina Rodrigues ${ }^{3}$, Ana Castro Rollo ${ }^{4}$

\section{RESUMO}

A psitacose, também conhecida como ornitose, é geralmente uma doença com manifestações sistémicas proeminentes e alguns sintomas respiratórios, causada por Chlamydia psittaci. Os pássaros psitacinos são o principal reservatório e meio de transmissão da doença para os humanos.

Descreve-se o caso clínico de uma doente de 50 anos, trabalhadora num armazém agro-avícola, que foi observada três vezes em contexto de urgência por quadro de dispneia, tosse seca, toracalgia, cansaço generalizado e febre. Relata-se o seu percurso e evolução até ao diagnóstico de pneumonia a Chlamydia psittaci.

Este relato de caso reforça a importância de realizar sempre uma adequada anamnese, revelando-se preponderante para o sucesso diagnóstico e terapêutica dirigida.

PALAVRAS-CHAVES: Chlamydia psittaci; Infecções Comunitárias Adquiridas; Pneumonia Bacteriana; Psitacose

1. Interno de Formação Específica em Medicina Geral e Familiar, USF Samora Correia, ACES Estuário do Tejo, Samora Correia, Portugal. 2. Interna de Formação Específica em Medicina Geral e Familiar, USF Terras de Cira, ACES Estuário do Tejo, Vila Franca de Xira, Portugal. 3. Interna de Formação Específica em Medicina Geral e Familiar, UCSP Azambuja, ACES Estuário do Tejo, Azambuja, Portugal. 4. Interna de Formação Específica em Medicina Geral e Familiar, USF Nova Era, ACES Tâmega II Vale do Sousa Sul, Paredes, Portugal. 


\section{ABSTRACT}

Psittacosis, also known as ornithosis, is a condition, caused by Chlamydia psittaci, which usually causes both prominent systemic manifestations and respiratory symptoms. This condition is transmitted to the vast majority of humans by psittaciformes birds.

In this article, we describe a clinical case of a 50-year-old patient, working in an agro-poultry warehouse, who was observed three times due to dyspnea, dry cough, chest pain, general tiredness and fever. Only after she have been submitted to additional tests, the diagnosis of pneumonia to Chlamydia psittaci was revealed.

With this case we aim to stress the fundamental role played by an adequate anamnesis and her importance for a successful diagnosis and concomitant targeted therapy.

KEYWORDS: Chlamydophila psittaci; Community-Acquired Infections; Pneumonia, Bacterial; Psittacosis

\section{INTRODUÇÃO}

A psitacose, também conhecida como ornitose, é uma infeção causada por Chlamydia psittaci (C. psittaci) transmitida aos seres humanos predominantemente a partir de pássaros psitacinos. Provocam uma doença disseminada caracterizada por pneumonite e que está englobada nas pneumonias atípicas. ${ }^{1}$ Caracteriza-se por um quadro com manifestações sistémicas proeminentes e alguns sintomas respiratórios. ${ }^{1}$ Numa meta-análise de estudos observacionais, a C. psittaci foi estimada como causadora de aproximadamente $1 \%$ dos casos de pneumonia adquirida na comunidade (PAC). Surtos ocorrem entre trabalhadores que manuseiam perus e patos em instalações de processamento de aves. No entanto, é difícil estabelecer a incidência e prevalência precisas da psitacose, provavelmente devido à falta de testes de rotina. ${ }^{2}$ A transmissão acontece, na maioria dos casos, por aerossóis, inalação de urina, fezes ou outras partículas contaminadas. Tem um período de incubação que varia de cinco a 14 dias, mas é extremamente variável, podendo estender-se por semanas em casos de infeção subaguda ou latente. Tem uma apresentação clínica semelhante a uma síndrome gripal.1,2 Pouca informação epidemiológica acerca deste agente está disponível para Portugal. Neste manuscrito, descrevemos um caso clínico de uma doente de 50 anos com pneumonia a C. psittaci.

\section{CASO CLÍNICO}

Doente do género feminino, 50 anos, casada, com três filhos. Apresenta como antecedentes pessoais obesidade grau II (Índice de massa corporal de 35,2), não fazendo nenhuma medicação crónica, sendo totalmente independente para as atividades de vida diária (AVD's).
Concluiu o sexto ano de escolaridade e trabalha num armazém agro-avícola desde há vários anos. Reside com o marido e com dois filhos, uma família classificada como nuclear, na fase VI do Ciclo de Vida de Duvall.

Foi observada num Serviço de Atendimento Permanente (SAP) por quadro de dispneia, tosse seca, toracalgia, cansaço generalizado e febre com três dias de evolução, tendo sido medicada sintomaticamente com paracetamol, tiocolquicosido e nimesulida. Não foi realizado qualquer meio complementar de diagnóstico (MCDT).

Por agravamento da sintomatologia, passados dois dias, foi novamente observada no Centro de Saúde (CS). Iniciou amoxicilina 875 mg + ácido clavulânico 125 mg, per os bi-diário (bid), e budesonida 160 нg/dose + formoterol 4,5 $\mathrm{\mu g} / \mathrm{dose}$, uma inalação bid.

Por manter agravamento progressivo do quadro clínico, apesar da terapêutica instituída, ao nono dia de doença e quinto dia de antibioterapia empírica dirigiu-se ao Serviço de Urgência (SU), onde realizou radiografia torácica, Fig. 1, que revelou "...opacidade na topografia do lobo superior direito, compatível com pneumonia lobar..." e análises clínicas cujos resultados estão na Tabela 1. Destaca-se marcada elevação da proteína $\mathrm{C}$ reativa (PCR) e das transaminases hepáticas. Realizou ainda ecografia abdominal que revelou "hepatomegalia homogénea com maior eixo de $22,5 \mathrm{~cm}$. Sem outros achados dignos de referência". Foi então medicada com levofloxacina 500 mg, per os de toma única diária (id), que cumpriu apenas 3 tomas por intolerância.

Apesar da terapêutica anterior instituída, a doente permaneceu sempre consideravelmente sintomática, com tosse seca, cansaço para as AVD's e dispneia. Dirigiu-se então pela segunda vez ao SU, no $12^{\circ}$ dia de doença, onde após uma anamnese mais detalhada foram pedidos 


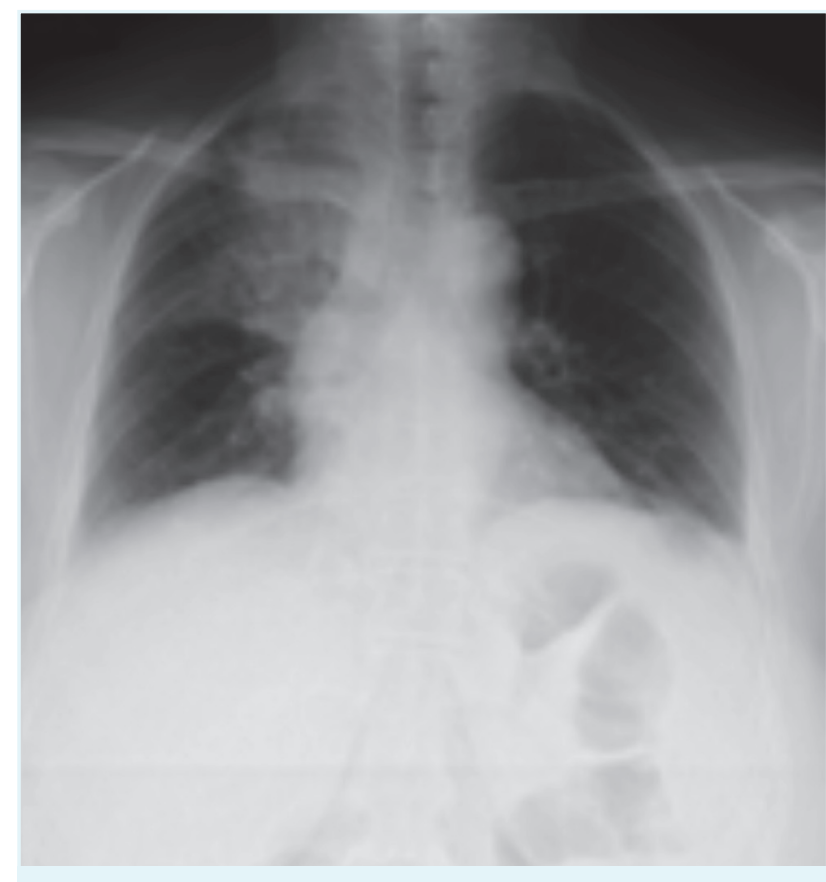

FIGURA 1. Radiografia torácica em SU.

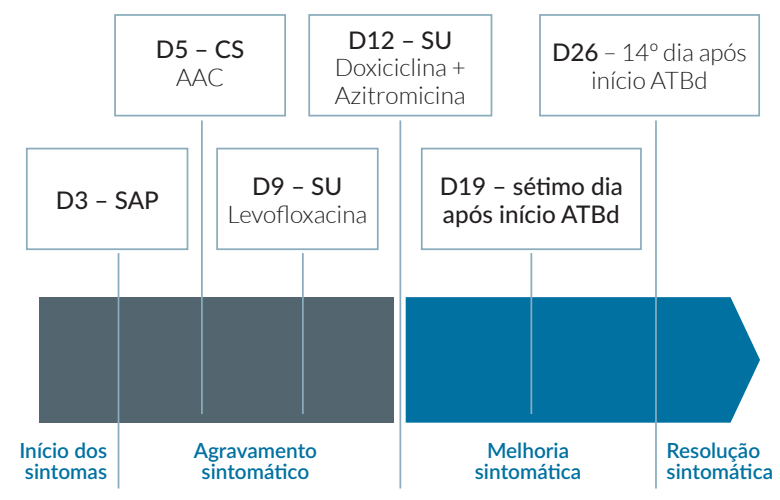

AAC - amoxicilina + ácido clavulânico; ATBd - antibioterapia dirigida; CS - Centro de Saúde; D - dia; SAP - Serviço de Atendimento Permanente; SU - Serviço de Urgência.

FIGURA 2. Representação gráfica do percurso e evolução da doente.

os anticorpos anti-Chlamydia psittaci (IgG e IgM) que se revelaram ambos positivos. Foi então medicada com doxiciclina $100 \mathrm{mg}$, per os bid, durante 10 dias, e azitromicina 500 mg, per os id, durante três dias.

Foi reportada uma melhoria progressiva do quadro clínico, encontrando-se completamente assintomática após sete dias do início da terapêutica dirigida. Nas análises de reavaliação, duas semanas após o início da terapêutica dirigida, observam-se parâmetros inflamatórios e de função hepática em perfil descendente (Tabela 1), com melhoria sintomática significativa. Na Fig. 2 está representado o percurso e evolução clínica da doente.

\section{DISCUSSÃO}

O agente causal da psitacose é a C. psittaci, bactéria gram-negativa, hospedeiro intracelular obrigatório. ${ }^{2-4} \mathrm{~A}$ maioria dos doentes com psitacose tem um histórico de contacto com pássaros. C. psittaci foi documentada em pelo menos 460 espécies de 30 ordens de aves, incluindo perus, faisões, galinhas ${ }^{5}$ e até avestruzes e pinguins. ${ }^{6}$ Em França, os patos mulard estão associados a doenças humanas, embora funcionem como reservatório ou portadores assintomáticos. Cada ordem de ave tende a ser infetada por um genótipo predominante de C. psittaci.7

O órgão humano mais acometido é o pulmão, manifestando-se como tosse seca e dispneia. Não existem características radiológicas que permitam diferenciar a pneumonia por psitacose da pneumonia por outras causas. Os principais diagnósticos diferenciais da psitacose são outras causas de pneumonia atípica. Os achados mais frequentes são consolidação segmentar (31\%) e consolidação lobar (21\%), as quais ocorrem principalmente nos lobos inferiores. ${ }^{1}$ A contagem de células leucocitárias é geralmente normal, podendo ocasionalmente haver marcada leucocitose. A PCR está frequentemente elevada. As enzimas hepáticas estão alteradas em aproximadamente metade dos pacientes hospitalizados, geralmente com elevação leve do aspartato aminotransferase e baixos níveis séricos de albumina. ${ }^{8}$

As tetraciclinas são o fármaco de eleição para o tratamento da psitacose. A doxiciclina (100 mg per os bid) geralmente produz uma resposta clínica rápida em pacientes com doença leve a moderada. Embora a duração ideal da terapia para a psitacose não tenha sido determinada, geralmente opta-se por um período entre 7 a 10 dias. Outros agentes têm sido propostos como alternativas. Os macrólidos são frequentemente usados no tratamento da PAC na ausência de um diagnóstico microbiológico e têm grande probabilidade de serem eficazes contra a psitacose. Um macrólido, como eritromicina ou azitromicina, é geralmente recomendado como terapia de segunda linha quando as tetraciclinas são contraindicadas. ${ }^{10,11}$

\section{CONCLUSÃO}

Este relato de caso demonstra a necessidade de realizar sempre uma adequada anamnese, revelando-se preponderante para o sucesso diagnóstico e terapêutica dirigida. Neste caso, dada a evolução clínica inicial desfavorável optou-se pela realização de antibioterapia dupla, com melhoria progressiva da sintomatologia. 
TABELA 1. Resultados laboratoriais no Serviço de Urgência.

\begin{tabular}{|c|c|c|c|}
\hline & $\begin{array}{c}9^{\circ} \mathrm{dia} \\
\text { de } \\
\text { doença }\end{array}$ & $\begin{array}{l}2 \text { semanas } \\
\text { após início } \\
\text { de terapêu- } \\
\text { tica dirigida }\end{array}$ & $\begin{array}{l}\text { Valores de } \\
\text { referência }\end{array}$ \\
\hline Leucócitos (103/ML) & 8,6 & 6,3 & $4,0-10,1$ \\
\hline 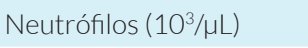 & 6,3 & 3,06 & $1,5-8,0$ \\
\hline Eosinófilos (103/uL) & 0,13 & 0,13 & $0,0-0,3$ \\
\hline Basófilos (103/ML) & 0,03 & 0,02 & $0,0-0,3$ \\
\hline Linfócitos (103/ML) & 1,69 & 2,72 & $0,8-4,0$ \\
\hline Monócitos (10³/uL) & 0,45 & 0,32 & $0,0-1,2$ \\
\hline $\begin{array}{l}\text { Aspartato } \\
\text { aminotransferase (UI/L) }\end{array}$ & 31 & 35 & $15-37$ \\
\hline $\begin{array}{l}\text { Gama-glutamil- } \\
\text {-transpeptidase (UI/L) }\end{array}$ & 127 & 73 & $5-55$ \\
\hline $\begin{array}{l}\text { Fosfatase alcalina (ALP) } \\
\text { (UI/L) }\end{array}$ & 197 & 130 & $50-136$ \\
\hline $\begin{array}{l}\text { Proteína C reativa (PCR) } \\
(\mathrm{mg} / \mathrm{dL})\end{array}$ & 29,33 & 1,42 & $0,06-1,00$ \\
\hline \multicolumn{4}{|c|}{ Gasometria arterial realizada ao $9^{\circ}$ dia de doença no SU } \\
\hline $\mathrm{pH}$ & & 7,522 & $7,37-7,45$ \\
\hline $\mathrm{pCO}_{2}(\mathrm{mmHg})$ & & 32,5 & $35-46$ \\
\hline $\mathrm{pO}_{2}(\mathrm{mmHg})$ & & 61,7 & $70-100$ \\
\hline $\mathrm{HCO}_{3}-(\mathrm{mmol} / \mathrm{L})$ & & 26,1 & $21-26$ \\
\hline $\mathrm{BE}(\mathrm{B})(\mathrm{mmol} / \mathrm{L})$ & & 3,7 & $-2-+3$ \\
\hline $\mathrm{SatO}_{2}(\%)$ & & 91,5 & $>96$ \\
\hline Lactato (mmol/L) & & 1,19 & $<1,8$ \\
\hline
\end{tabular}

$\mathrm{pO}_{2}$ (pressão parcial de oxigénio); $\mathrm{pCO}_{2}$ (pressão parcial de dióxido de carbono); $\mathrm{HCO}_{3}$ (bicarbonato); $\mathrm{BE}$ (base excess); $\mathrm{SatO}_{2}$ (saturação de oxigénio arterial)

A psitacose é um diagnóstico diferencial importante a ser considerado em situações de pneumonia comunitária que não responde à antibioterapia convencional, que evolui de modo insatisfatório e cuja epidemiologia é positiva para exposição às aves. O tratamento precoce é fundamental no prognóstico devido à boa resposta terapêutica.

\section{RESPONSABILIDADES ÉTICAS}

CONFLITOS DE INTERESSE: Os autores declaram a inexistência de conflitos de interesse na realização do presente trabalho.

FONTES DE FINANCIAMENTO: Não existiram fontes externas de financiamento para a realização deste artigo.

CONFIDENCIALIDADE DOS DADOS: Os autores declaram ter seguido os protocolos da sua instituição acerca da publicação dos dados de doentes.

CONSENTIMENTO: Consentimento do doente para publicação obtido.

PROVENIÊNCIA E REVISÃO POR PARES: Não comissionado; revisão externa por pares.

\section{ETHICAL DISCLOSURES}

CONFLICTS OF INTEREST: The authors have no conflicts of interest to declare.

FINANCING SUPPORT: This work has not received any contribution, grant or scholarship.

CONFIDENTIALITY OF DATA: The authors declare that they have followed the protocols of their work center on the publication of data from patients.

PATIENT CONSENT: Consent for publication was obtained.

PROVENANCE AND PEER REVIEW: Not commissioned; externally peer reviewed.

\section{REFERÊNCIAS}

1. Cadario ME, Frutos MC, Arias MB, Origlia JA, Zelaya V, Madariaga MJ, et al. Epidemiological and molecular characteristics of Chlamydia psittaci from 8 human cases of psittacosis and 4 related birds in Argentina. Rev Argent Microbiol. 2017; 49:323. doi: 10.1016/j.ram.2017.04.001.

2. Verweij PE, Meis JF, Eijk R, Melchers WJ. Severe human psittacosis requiring artificial ventilation: case report and review. Clin Infect Dis. 1995; 20:440-2.

3. Herring AJ. The molecular biology of chlamydia $3 / 4$ A brief overview. J Infect 1992; 25:1-10.

4. Peeling RW, Brunham RC. Chlamydiae as pathogens: new species and new issues. Emerg Infect Dis. 1996; 4:307-19.

5. Čechová L, Halánová M, Babinská I, Danišová O, Bartkovský M, Marcinčák S, et al. Chlamydiosis in farmed chickens in Slovakia and zoonotic risk for humans. Ann Agric Environ Med. 2018; 25:320-5. doi: 10.26444/aaem/82948.

6. Kaleta EF, Taday EM. Avian host range of Chlamydophila spp. based on isolation, antigen detection and serology. Avian Pathol. 2003; 32:435-61. doi: 10.1080/03079450310001593613.

7. Vorimore F, Thébault A, Poisson S, Cléva D, Robineau J, de Barbeyrac B,et al. Chlamydia psittaci in ducks: a hidden health risk for poultry workers. Pathog Dis. 2015; 73:1-9. doi: 10.1093/ femspd/ftu016.

8. Crosse BA. Psittacosis: a clinical review. J Infect. 1990; 21:251.

9. Yung AP, Grayson ML. Psittacosis--a review of 135 cases. Med J Aust. 1988; 148:228-33.

10. Hammers-Berggren S, Granath F, Julander I, Kalin M. Erythromycin for treatment of ornithosis. Scand J Infect Dis. 1991; 23:159-62. doi: 10.3109/00365549109023394.

11. File TM, Tan JS, Plouffe JF. The role of atypical patogens: Mycoplasma pneumoniae, Chlamydia pneumoniae, and Legionella pneumophila in respiratory infection. Infect Dis Clin North Am. 1998; 12:569-91.

12. Byrom NP, Walls J. Fulminant psittacosis. Lancet. 1979; i: 3536.

13. Riantawan P, Nunthapisud P. Psittacosis pneumonia: a case and review of the literature. J Med Assoc Thai. 1996; 79:55-9. 